\title{
Targeted quantitative profiling of metabolites and gene transcripts associated with 4-aminobutyrate (GABA) in apple fruit stored under multiple abiotic stresses
}

\author{
Carolyne J. Brikis ${ }^{1}$, Adel Zarei ${ }^{1}$, Greta Z. Chiu ${ }^{1}$, Kristen L. Deyman', Jingyun Liu', Christopher P. Trobacher ${ }^{1}$, \\ Gordon J. Hoover', Sanjeena Subedi², Jennifer R. DeEll', Gale G. Bozzo ${ }^{1}$ and Barry J. Shelp ${ }^{1}$
}

\begin{abstract}
4-Aminobutyrate accumulates in plants under abiotic stress. Here, targeted quantitative profiling of metabolites and transcripts was conducted to monitor glutamate- and polyamine-derived 4-aminobutyrate production and its subsequent catabolism to succinate or 4-hydroxybutyrate in apple (Malus $\mathrm{x}$ domestica Borkh.) fruit stored at $0{ }^{\circ} \mathrm{C}$ with $2.5 \mathrm{kPa} \mathrm{O}$ and 0.03 or $5 \mathrm{kPa} \mathrm{CO}$ for 16 weeks. Low-temperature-induced protein hydrolysis appeared to be responsible for the enhanced availability of amino acids during early storage, and the resulting higher glutamate level stimulated 4-aminobutyrate levels more than polyamines. Elevated $\mathrm{CO}_{2}$ increased the levels of polyamines, as well as succinate and 4-hydroxybutyrate, during early storage, and 4-aminobutyrate and 4-hydroxybutyrate over the longer term. Expression of all of the genes likely involved in 4-aminobutyrate metabolism from glutamate/polyamines to succinate/4-hydroxybutyrate was induced in a co-ordinated manner. $\mathrm{CO}_{2}$-regulated expression of apple GLUTAMATE DECARBOXYLASE 2, AMINE OXIDASE 1, ALDEHYDE DEHYDROGENASE 1OA8 and POLYAMINE OXIDASE 2 was evident with longer term storage. Evidence suggested that respiratory activities were restricted by the elevated $\mathrm{CO}_{2} / \mathrm{O}_{2}$ environment, and that decreasing $\mathrm{NAD}^{+}$availability and increasing NADPH and NADPH/NADP ${ }^{+}$, respectively, played key roles in the regulation of succinate and 4-hydroxybutyate accumulation. Together, these findings suggest that both transcriptional and biochemical mechanisms are associated with 4-aminobutyrate and 4-hydroxybutyrate metabolism in apple fruit stored under multiple abiotic stresses.
\end{abstract}

\section{Introduction}

The non-protein amino acid 4-aminobutyrate (GABA) is derived from glutamate in plants exposed to various abiotic stresses via activity of the enzyme glutamate

\footnotetext{
Correspondence: Barry J. Shelp (bshelp@uoguelph.ca)

${ }^{1}$ Department of Plant Agriculture, University of Guelph, Guelph, Ontario

N1G 2W1, Canada

${ }^{2}$ Department of Mathematical Sciences, Binghamton University, Binghamton, NY 13902, USA

Full list of author information is available at the end of the article.

These authors contributed equally: Carolyne J. Brikis, Adel Zarei
}

decarboxylase (GAD), which can be activated by $\mathrm{Ca}^{2+} /$ calmodulin or stimulated by cytosolic acidification ${ }^{1}$. In turn, GABA is converted to succinic semialdehyde (SSA) via GABA transaminase (GABA-T) and then to succinate via $\mathrm{NAD}^{+}$-dependent succinic semialdehyde dehydrogenase (SSADH) or to 4-hydroxybutyrate (GHB) via NADPH-dependent glyoxylate/succinic semialdehyde reductase $(\mathrm{GLYR})^{1-3}$. Much less attention has been paid to the derivation of GABA from polyamines ${ }^{1,4}$. This can occur by the terminal catabolism of putrescine (Put) to 4-

\section{(c) The Author(s) 2018}

(c) (i) Open Access This article is licensed under a Creative Commons Attribution 4.0 International License, which permits use, sharing, adaptation, distribution and reproduction cc) in any medium or format, as long as you give appropriate credit to the original author(s) and the source, provide a link to the Creative Commons license, and indicate if changes were made. The images or other third party material in this article are included in the article's Creative Commons license, unless indicated otherwise in a credit line to the material. If material is not included in the article's Creative Commons license and your intended use is not permitted by statutory regulation or exceeds the permitted use, you will need to obtain permission directly from the copyright holder. To view a copy of this license, visit http://creativecommons.org/licenses/by/4.0/. 
aminobutanal $/ \Delta^{1}$-pyrroline via $\mathrm{O}_{2}$-dependent coppercontaining amine oxidases $(\mathrm{AO})$ and spermidine to 4aminobutanal via FAD-dependent polyamine oxidases $(\mathrm{PAO})^{1,4,5}$, or the non-enzymatic decarboxylation of proline to pyrrolidin-1-yl, which is easily converted to 4aminobutanal ${ }^{6}$. In turn, 4-aminobutanal can be converted to GABA via members of the aldehyde dehydrogenase (ALDH) 10 family (i.e., $\mathrm{NAD}^{+}$-dependent ALDH10A8 and ALDH10A9) $)^{7,8}$.

In developed countries apple (Malus $\times$ domestica Borkh.) fruit are stored under controlled-atmosphere (CA) conditions (i.e., low $\mathrm{O}_{2}$ and elevated $\mathrm{CO}_{2}$ ) at low temperature to delay ripening ${ }^{9,10}$. Low temperature, low $\mathrm{O}_{2}$ or elevated $\mathrm{CO}_{2}$ have been associated with GABA accumulation in many plant systems $\mathrm{s}^{1,11-15}$ and limited $\mathrm{O}_{2}$ availability has been associated with changes in redox balance ${ }^{16,17}$, which may in turn influence the activities of AO, ALDH10A, SSADH and GLYR ${ }^{1,18,19}$. If so, low- $\mathrm{O}_{2}$ and elevated- $\mathrm{CO}_{2}$ storage of apple fruit at low temperature could inhibit the production of GABA from polyamines and divert glutamate-derived GABA catabolism to $\mathrm{GHB}^{20}$.

Many of the experimental approaches that have been used to investigate the pathways associated with GABA metabolism in plants subjected to abiotic stress ${ }^{1,20}$ are not suited or readily adapted to study their relative importance in apples. For example, mutants are not available, and amine oxidase inhibitors and radiolabelled precursors cannot be supplied to intact fruit without perturbing the internal gaseous environment. Untargeted metabolomics and enzymatic approaches could provide a global view of the metabolism in the stressed fruit; however, the incomplete profiling of important GABA pathway metabolites and the presence of multiple enzyme forms, respectively, could severely limit the interpretation of these results. In the present study, we utilized targeted quantitative profiling of metabolites and gene transcripts in cultivar 'Empire' apple fruit to monitor GABA metabolism during 16 weeks of postharvest storage under multiple abiotic stress conditions $\left(0^{\circ} \mathrm{C}, 2.5 \mathrm{kPa} \mathrm{O}\right.$ and 0.03 or $5 \mathrm{kPa} \mathrm{CO}$ ). Intact fruit were analyzed to eliminate any impact of the mechanical stress that would occur during separation of the peel and flesh ${ }^{15,21,22}$. Linear and multivariate correlation analyses were used to identify if any metabolites and gene transcripts were specifically associated with low-temperature/low- $\mathrm{O}_{2}$ conditions in the absence or presence of elevated $\mathrm{CO}_{2}$.

\section{Materials and methods}

\section{Controlled-atmosphere storage}

The harvest, low-temperature CA storage, and quality assessment in 2009 of the apple (Malus x domestica Borkh. cultivar 'Empire') fruit have been described elsewhere ${ }^{9}$. Here we chose the fruit collected from orchard 2.
Immediately prior to storage, eight apples were randomly sampled from the bulk apples for assessment of physiological disorders. Four apples were also sampled and rapidly frozen in liquid $\mathrm{N}_{2}$ for assessment of metabolite and gene transcript levels. The remaining apples were stored at $0{ }^{\circ} \mathrm{C}$ in two $\mathrm{CA}$ rooms (i.e., treatment blocks). Briefly, within each CA room, two random duplicate chambers were supplied with either 0.03 (control) or 5 $\left(\mathrm{CO}_{2}\right.$-treated) $\mathrm{kPa} \mathrm{CO}_{2}$ in combination with $2.5 \mathrm{kPa} \mathrm{O}$ (i.e., a split-plot design) for $16 \mathrm{wk}$. At several times during storage, eight apples were randomly sampled from each treatment replicate for assessment of physiological disorders, and four apples (i.e., subsamples) were randomly sampled from each treatment replicate and rapidly frozen in liquid $\mathrm{N}_{2}$. All frozen apples were stored for several months before being individually pulverized to powder using an arbor press, taking care to ensure that thawing did not occur, before being stored at $-80^{\circ} \mathrm{C}$. None of the freshly collected or stored fruit showed signs of flesh browning or senescent breakdown ${ }^{21}$, but external $\mathrm{CO}_{2}$ injury (i.e., bronze- to brown-colored, rough uneven lesion with sunken areas on the peel) was evident on fruit receiving $5 \mathrm{kPa} \mathrm{CO}$; the incidence was 37, 51, 70 and $85 \%$, respectively, after $2,4,8$ and 16 weeks of storage ${ }^{9}$.

\section{Extraction and analysis of metabolites}

The frozen apple fruit powders were extracted within $1-3$ years of harvest using various protocols, depending on the metabolites under consideration. The levels of various amino acids, including GABA, and the free forms of putrescine, spermidine and spermine were determined by reverse-phase high performance liquid chromatography as described elsewhere ${ }^{14,23}$. Detailed protocols for the extraction and GC-MS determination of GHB, and the enzymatic determination of succinate and pyridine dinucleotides are given in the Supplementary Information Materials and Methods S1.

\section{RNA extraction and CDNA synthesis}

RNA was isolated from the frozen apple fruit powders for three treatment blocks within a year of harvest essentially as described elsewhere ${ }^{15}$. RNA integrity was verified using formaldehyde RNA gel electrophoresis. RNA $(1 \mu \mathrm{g})$ was treated with DNAase I using the Turbo DNA-free kit (Applied Biosystems) according to the manufacturer's protocol. For first strand cDNA synthesis, 10-100 ng total RNA was incubated with oligo(dT) 20 and Superscript III RT (Invitrogen) at $50^{\circ} \mathrm{C}$, followed by $55^{\circ} \mathrm{C}$ for $30 \mathrm{~min}$.

\section{Identification of apple genes}

The apple genes for three GADs, two GABA-Ts, two GLYRs, five $A O$ s and two $A L D H 1 O A$ s have been reported elsewhere ${ }^{5,7,15,24}$. Methods for identifying the putative 
apple SSADH, ALANINE TRANSAMINASE and POLYAMINE OXIDASE genes are described in Supplementary Information Materials and Methods S2.

\section{Quantitative real-time PCR}

Primers used for quantitative polymerase chain reaction (qPCR) were designed using Primer Express 3 software (Applied Biosystems) with the following default conditions: $60^{\circ} \mathrm{C}$ primer melting temperature; $50-80 \mathrm{bp}$ amplicon length; and, $40-60 \%$ primer GC content. The list of primers used here is provided in Supplementary Information Table S3. It was not possible to design primers that enabled separate monitoring of the two distinct apple GABA-T genes ${ }^{15}$. Quantitative PCR was performed in a 96-well plate iQ5 Multicolor Real-Time PCR Detection System (BioRad) as previously described ${ }^{5}$. Dissociation curve analysis was performed after 40 cycles of qPCR to ensure the presence of a single PCR product. Efficiency of the primer pairs ranged from 90 to $105 \%$. The data were analyzed and relative expression calculated using the $2^{-\Delta \mathrm{C}_{\mathrm{T}}}$ method $^{25}$. The expression of each target gene was normalized to the housekeeping apple ELONGATION FACTOR-1 $\alpha(E F-1 \alpha)$ gene (MD0000294265) $)^{26,27}$. Each treatment replicate was analyzed in duplicate.

\section{Statistical analysis}

The data were analyzed as a completely randomized design of two blocks (i.e., replicate CA rooms) with a splitplot design using ANOVAs (Proc Mixed method of SAS ${ }^{\oplus}$ software $^{28}$ ). Since there was no block effect for the incidence of external and internal disorders, time course data for levels of metabolites and transcripts are presented as means of four and three treatment replicates, respectively. Four apples were subsampled periodically from each treatment replicate; these were considered as repeated measures. Assumptions of randomness, homogeneity, and independence of errors were confirmed using plots of residuals, as well as a Shapiro-Wilk test for normality. Treatment means were compared within and across weeks using the Tukey's Least Significance Difference method for multiple comparisons at the $95 \%$ confidence level.

The relationships among metabolites and transcripts were assessed by Pearson's correlation test using $\mathrm{R}^{29}$ and corrected for false discovery rate $^{30}$. The relationships among metabolites and transcripts was also assessed by principal component analysis (PCA) using $\mathrm{R}^{29}$. Replicates with missing subsample values for a variable/treatment were removed from the analysis. In some cases, the data set for each variable was not normally distributed when expressed on their original scale; therefore, the Shapiro-Wilk test for normality was performed on each variable individually. If a variable deviated from normality, boxcox transformation was used to identify transformed variables that approximate normality. Then the variables were scaled to a mean of 0 and a variance of 1 prior to PCA.

\section{Results \\ Levels and ratios of pyridine dinucleotides}

The major non-phosphorylated and phosphorylated pyridine dinucleotides in both freshly harvested and stored 'Empire' fruit were the reduced forms. The concentrations of $\mathrm{NAD}^{+}, \mathrm{NADH}$ and $\mathrm{NADP}^{+}$in both control and $\mathrm{CO}_{2}$-treated fruit generally decreased with storage time, whereas NADPH increased, resulting in lower levels of $\operatorname{NAD}(\mathrm{H})$ and higher levels of $\mathrm{NADP}(\mathrm{H})$ (Fig. 1a-f). Overall, there was an approximately $60 \%$ decrease in the concentrations of total pyridine dinucleotides (Fig. 1g), a $50 \%$ decrease in the NADH/NAD ${ }^{+}$ratio (Fig. 1i), and a two-fold increase in NADPH/NADP ${ }^{+}$ratio (Fig. 1h). The $\mathrm{NADH} / \mathrm{NAD}^{+}$and $\mathrm{NADPH} / \mathrm{NADP}^{+}$ratios ranged from 20-70 and 60-150, respectively.

\section{Levels of GABA and closely related metabolites and gene transcripts}

The major amino acids in both freshly harvested and stored fruit were aspartate, asparagine and glutamate (Supplementary Information Table S4). In control fruit, the concentrations of total amino acids (TAA), GABA and GABA-related amino acids (i.e., glutamate and alanine) increased to a maximum within 2-4 weeks, and then declined to their original levels after 8-16 weeks (Fig. 2a-d)). There was also a transient peak in GHB, but this was delayed in comparison to the amino acids (Fig. 2e). The concentration of succinate was low and steady over the entire storage period (Fig. 2f). Storage with $5 \mathrm{kPa} \mathrm{CO}_{2}$ significantly increased the concentrations of alanine, GHB and succinate early during storage, and GHB and GABA later in the storage period. Notably, the concentration of GHB is much lower than succinate and also increasing with high $\mathrm{CO}_{2}$ when succinate is decreasing.

The transcript abundance of $A L A-T$, which could be considered as a reliable indicator of hypoxic conditions ${ }^{31}$, reached a maximum in the control within $2 \mathrm{wk}$ of storage, and then levelled off for the remaining storage time (Fig. 3i). Treatment with $\mathrm{CO}_{2}$ further enhanced $A L A-T$ transcript abundance at 4-8 weeks. Of the GAD transcripts in the control, GAD1 was most abundant, GAD2 was moderately abundant, and GAD3 was lowly abundant (Fig. $3 \mathrm{a}-\mathrm{c}$ ). The abundance of GAD1 and GAD2 transcripts increased linearly up to 4-8 weeks and then levelled off, whereas the abundance of GAD3 transcript declined after a transient peak. Treatment with $\mathrm{CO}_{2}$ delayed the increase in GAD1 transcript abundance, and increased the maximal abundance of GAD2 transcript late in the storage period. GABA-T1,2 (Fig. 3d) and SSADH1 

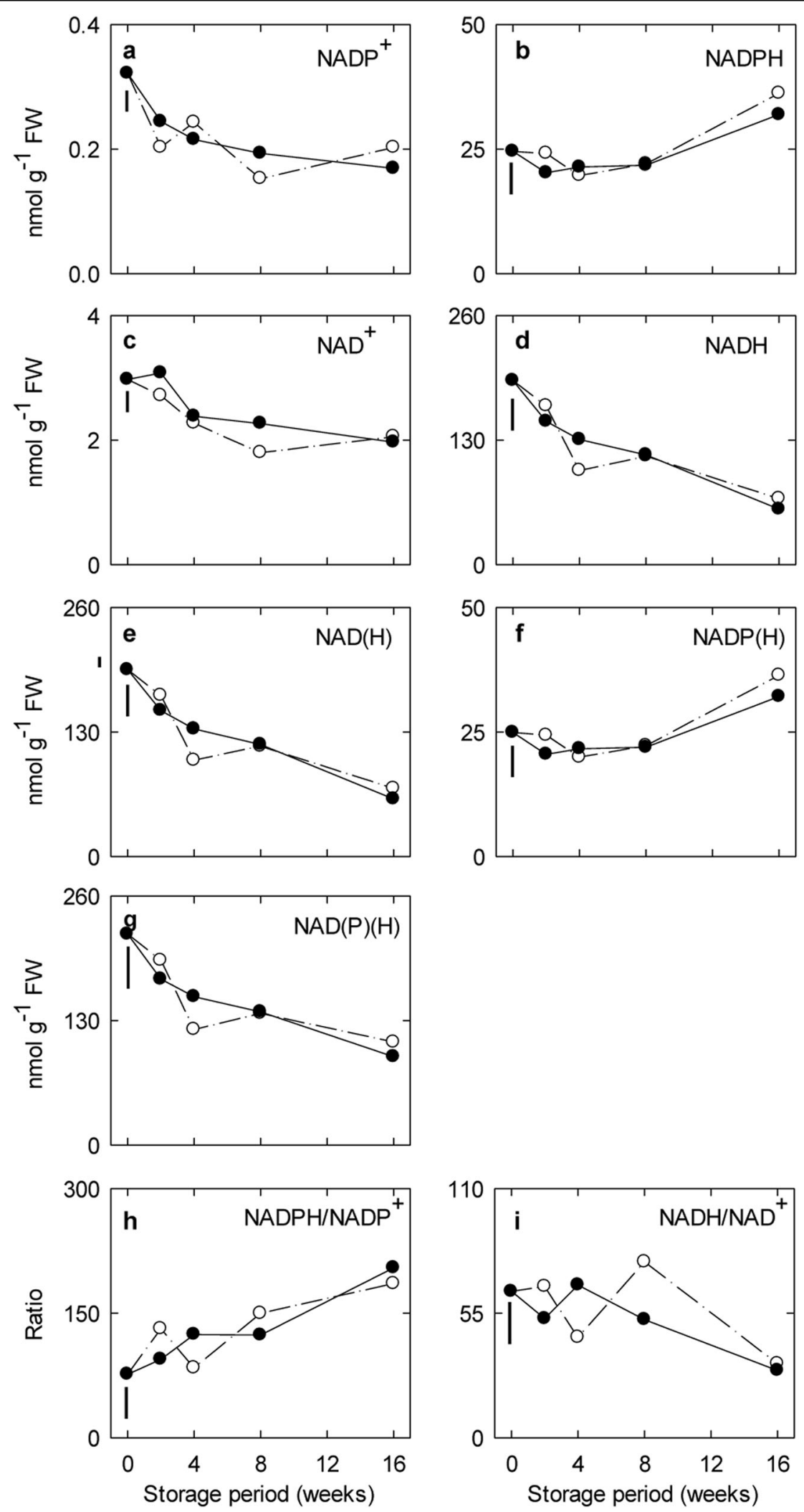

Fig. 1 (See legend on next page.) 
(see figure on previous page)

Fig. 1 Impact of elevated $\mathrm{CO}_{2}$ on the pyridine dinucleotide status in 'Empire' apple fruit under low-temperature/low- $\mathrm{O}_{2}$ storage for up to 16 weeks. Panels a-i represent time-course profiles for NADP +, NADPH, NAD+, NADH, NAD(H), NADP(H), NAD(P)(H), NADPH/NADP+ and NADH/ $\mathrm{NAD}+$, respectively. Storage conditions: $0{ }^{\circ} \mathrm{C}, 2.5 \mathrm{kPa} \mathrm{O}_{2}$ and $5 \mathrm{kPa}(\mathbf{O})$ or $0.03 \mathrm{kPa}(\mathrm{O}) \mathrm{CO}_{2}$. All the data represent the mean of four treatment replicates, each being the average of three to four subsamples. The error bar below 0 week represents the least significant difference at the $P \leq 0.05$

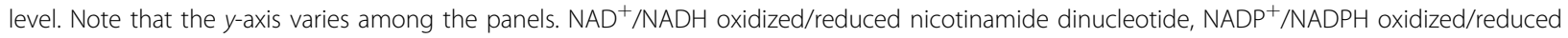
nicotinamide dinucleotide phosphate, NAD $(H)$ total oxidized/reduced nicotinamide dinucleotide, NADP $(H)$ total oxidized/reduced nicotinamide dinucleotide phosphate, $N A D(P)(H)$ total oxidized/reduced nicotinamide dinucleotide (phosphate)
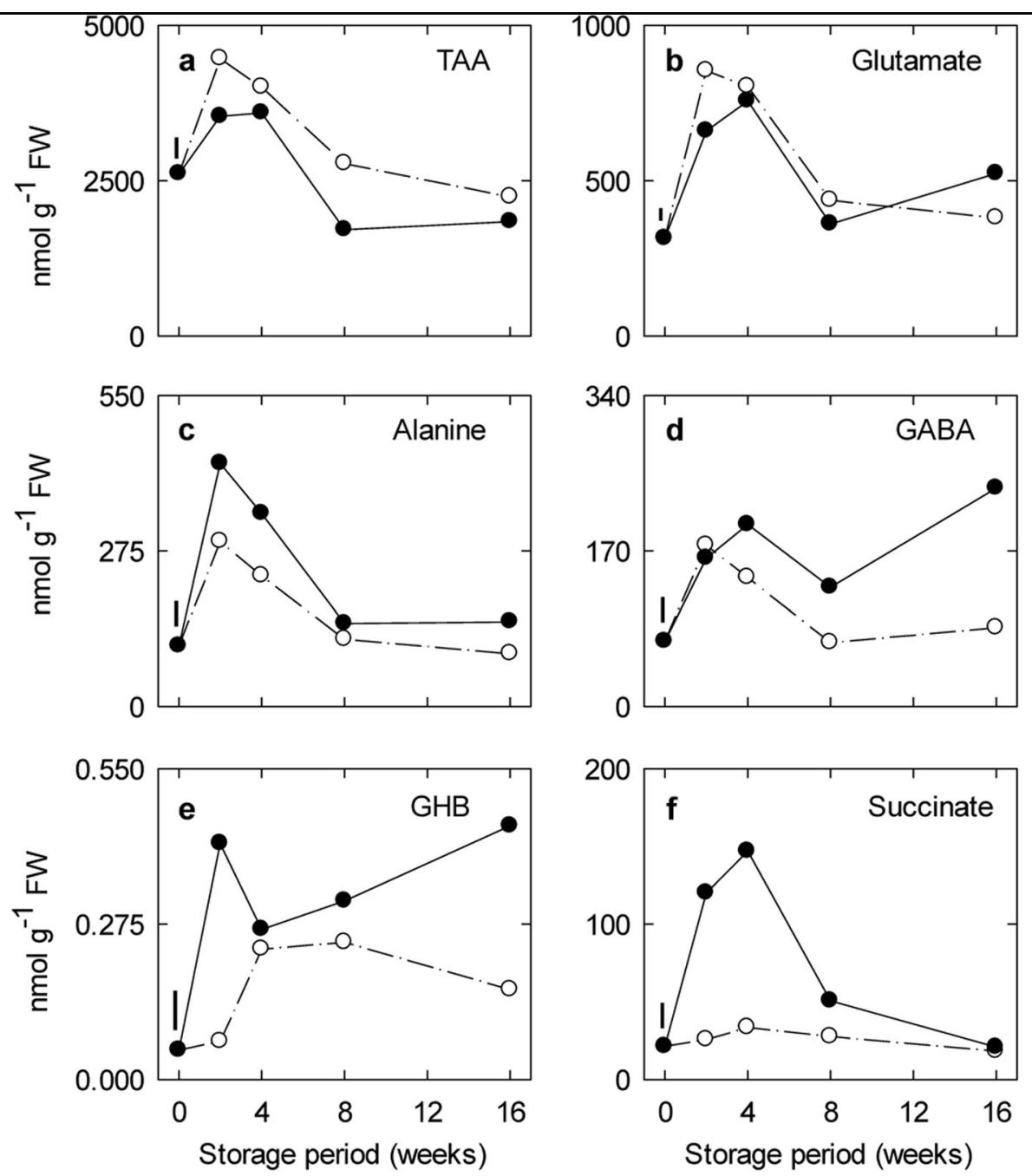

Fig. 2 Impact of elevated $\mathrm{CO}_{2}$ on the levels of GABA and related metabolites in 'Empire' apple fruit under low-temperature/low- $\mathrm{O}_{2}$ storage for up to 16 weeks. Panels a-f represent time-course profiles for TAA, glutamate, alanine, GHB and succinate, respectively. Storage conditions: $0^{\circ} \mathrm{C}$, $2.5 \mathrm{kPa} \mathrm{O}_{2}$ and $5 \mathrm{kPa}(-)$ or $0.03 \mathrm{kPa}(\mathrm{O}) \mathrm{CO}_{2}$. All the data represent the mean of four treatment replicates, each being the average of three to four subsamples. The error bar above 0 wk represents the least significant difference at the $P \leq 0.05$ level. Note that the $y$-axis varies among the panels. GABA 4-aminobutyrate, GHB 4-hydroxybutyrate, TAA total amino acids

(Fig. 3g) transcripts were moderately abundant in the control and displayed similar $\mathrm{CO}_{2}$ responses and patterns as GAD1, whereas the SSADH 2 (Fig. 3h) transcript was much less abundant and rapidly declined in a $\mathrm{CO}_{2}$-independent manner with storage time. The transcripts for
GLYR1 and GLYR2 were moderately abundant and transiently increased by $\sim 1$-fold early in the storage period (Fig. 3e-f). Treatment with $\mathrm{CO}_{2}$ decreased abundance of the GLYR1 and GLYR2 transcripts during mid and early storage, respectively. 


\section{In silico analysis of putative apple PAOs}

In silico analysis revealed that the six putative apple $P A O$ genes encode proteins ranging from 488 to 533 amino acids and from 24\% (PAO1 and PAO6) to $91 \%$ (PAO3 and PAO4) sequence identity (Supplementary Information Table S5). Apple PAO1 is $72 \%$ identical to Arabidopsis PAO1, apple PAO2 is $79 \%$ identical to Arabidopsis $\mathrm{PAO} 2$, and apple $\mathrm{PAO} 3$ is $60 \%$ identical to Arabidopsis PAO3. In particular, apple PAO5 and apple PAO6 have a high degree of identity (90\%) to each other, as well as Arabidopsis PAO5.

Sequence comparison and phylogenetic analysis of the six putative apple $P A O$ genes to known Arabidopsis PAOs reveal that they can be divided into three distinct groups as described for Arabidopsis ${ }^{32}$. Apple PAO2, PAO3 and $\mathrm{PAO} 4$, together with Arabidopsis PAO2, PAO3 and $\mathrm{PAO} 4$ form a cluster possessing a peroxisome targeting signal 1 (Supplementary Information Figure S1a-b). Arabidopsis members of this group are localized in the peroxisome ${ }^{4}$, and similar subcellular localization is predicted for apple members (PAO2-4) of this group. Moreover, apple PAO1 clusters with apple PAO1, whereas apple PAO5, apple PAO6 and Arabidopsis POA5 cluster separately. Arabidopsis PAO1 and PAO5 appear to encode cytosolic proteins ${ }^{4}$; therefore, apple PAO5 and PAO6 are predicted to be cytosolic.

\section{Levels of polyamines and expression of genes associated with their catabolism to GABA}

The major polyamines in both freshly harvested and stored fruit were putrescine and spermidine, with minor concentrations of spermine. The concentrations of putrescine and spermidine were relatively steady in the control over the storage period, whereas spermine slowly declined (Fig. 4a-d). Treatment with $\mathrm{CO}_{2}$ increased the concentrations of all polyamines early in the storage period, but only spermine was higher than the control over the entire period. In general, concentrations of the polyamines were much lower than those for the GABArelated amino acids (Fig. $2 \mathrm{~b}-\mathrm{d}$ )

Of the six apple $P A O$ genes identified, only the transcripts for $P A O 2$ and $P A O 4$ genes were readily detected in fruit (Fig. 5a, b). The PAO2 transcript was slightly more abundant than the PAO4 transcript, although both peaked midway through the storage period. The $A O 2$ transcript was the most abundant of the five apple $A O$ genes, and peaked late in storage (Fig. $5 \mathrm{c}-\mathrm{e}$ ). The $A O 1$ transcript was moderately abundant and peaked within $2-4$ weeks. Any significant responses of these aforementioned $P A O$ and $A O$ transcripts to elevated $\mathrm{CO}_{2}$ seemed to be transient. The AO3-5 transcripts were present in low abundance and peaked transiently at 4-8 weeks; $A O 4$ appeared to show $\mathrm{CO}_{2}$-dependent stimulation during late storage (Fig. $5 \mathrm{e}-\mathrm{g}$ ). The ALDH1OA transcripts were moderately abundant and peaked by $2-4$ weeks, although a positive response to elevated $\mathrm{CO}_{2}$ tended to be delayed (Fig. 5h-i).

\section{Correlation and principal component analyses of metabolite and gene transcript levels}

Correlation analysis was performed on the entire data set of metabolites and gene transcripts from apples subjected to low-temperature/low- $\mathrm{O}_{2}$ storage at two $\mathrm{CO}_{2}$ levels by calculation of the Pearson's correlation coefficient for each metabolite/metabolite or metabolite/transcript pair (Fig. 6a). Notably, GABA and GHB were not significantly correlated with each other, nor with any of the other metabolites measured, including glutamate and $\mathrm{NADPH} / \mathrm{NADP}^{+}$. Positive correlations were found among various metabolites and transcripts: glutamate with alanine; alanine with glutamate, TAA, succinate and $G A D 1$; succinate with alanine, putrescine, spermine and total polyamines; total polyamines with succinate, putrescine, spermidine and spermine; putrescine with succinate, spermine and total polyamines; spermidine with total polyamines; spermine with succinate, putrescine and total polyamines; and, spermine with putrescine, spermidine and total polyamines. NADPH/NADP ${ }^{+}$was positively correlated with NADPH, NADP ${ }^{+}$and NADP $(\mathrm{H})$, and negatively correlated with $\mathrm{NAD}^{+}$. Also, there were significant positive correlations among various transcripts: GAD1 with GABA-T, SSADH1, AO2, $A L D H 10 A 8$ and ALDH1OA9; GABA-T with GAD1, SSADH1, AO2 and ALDH1OA8, ALDH1OA9 and PAO4; GLYR2 with SSADH1, AO4 and ALDH1OA9; SSADH1 with GAD1, GABA-T, GLYR2, AO2, AO4, ALDH1OA9, $A L D H 1 O A 8$ and PAO2; AO2 with GAD1, GABA-T, SSADH1, ALDH1OA8 and ALDH1OA9; AO4 with SSADH1, AO5, GLYR2 and ALDH1OA9; ALDH1OA9 with GAD1, GABA-T, GLYR2, SSADH1, AO2 and AO4, ALDHA8 and PAO4; ALDH1OA8 with GAD1, GABA-T, SSADH1, AO2, ALDH1OA9 and PAO4; PAO2 with SSADH1; PAO4 with GABA-T, ALDH1OA9 and $A L D H 10 A 8$; and, SSADH2 with GAD3.

The metabolite and transcript data set was also examined by PCA. The score plot suggests that PC1 captures the variability between early and late storage periods, and PC2 captures the variability between $\mathrm{CO}_{2}$ treatments (Fig. 6b). Hence, the biological variables in the loading plot can be discussed in these terms (Fig. 6c). GABA responded slightly to $\mathrm{CO}_{2}$, but not storage, whereas $\mathrm{GHB}$ responded slightly and moderately to storage and $\mathrm{CO}_{2}$, respectively. The pyridine dinucleotides and the $\mathrm{NAD}(\mathrm{P})$ $\mathrm{H} / \mathrm{NAD}(\mathrm{P})^{+}$ratio moderately responded to storage, and $\mathrm{NADP}^{+}$in particular strongly responded to $\mathrm{CO}_{2}$. Several metabolites (i.e., succinate, spermine, putrescine, alanine and glutamate), including TAA, moderately to strongly responded to storage, and succinate, putrescine and 

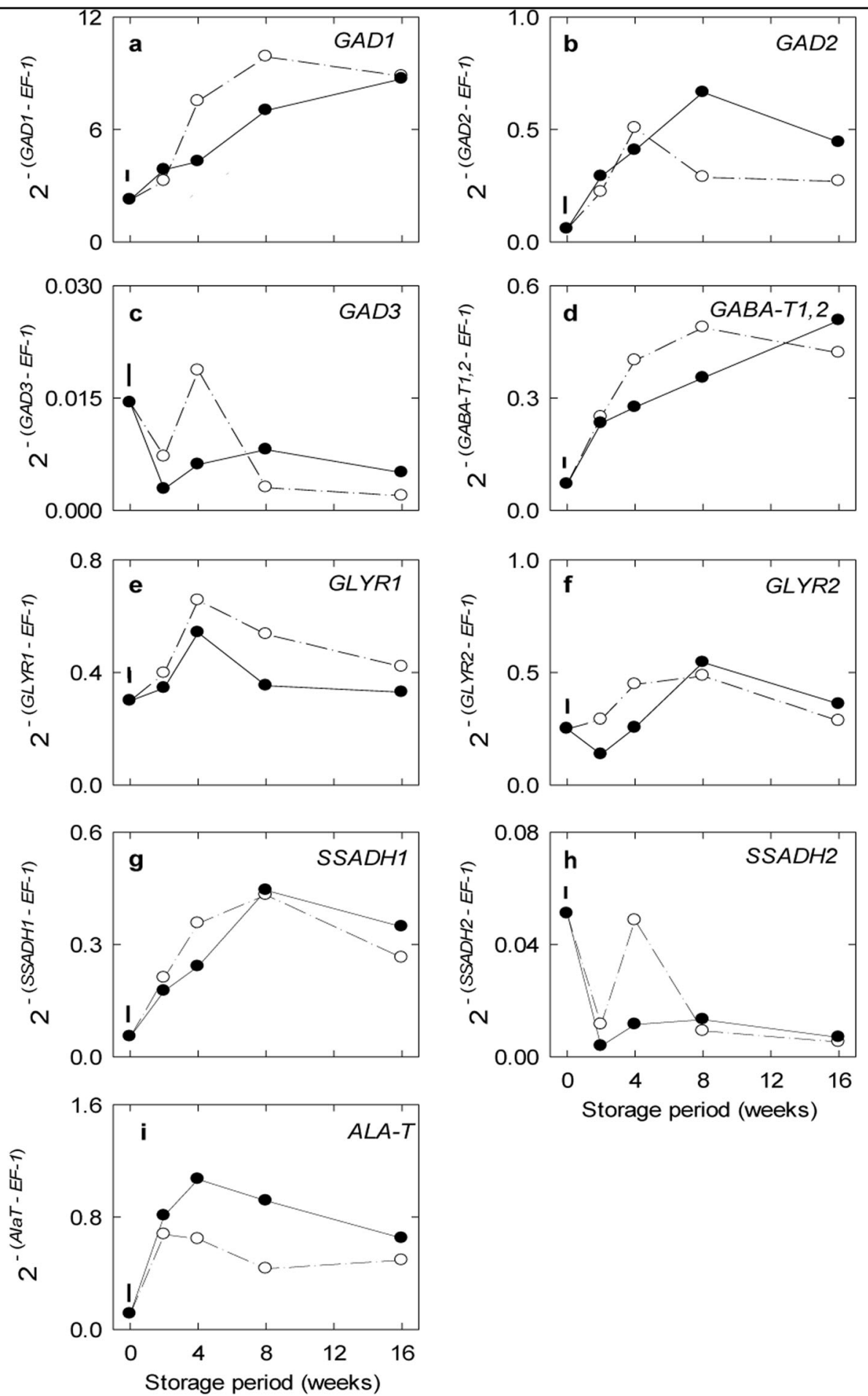

Fig. 3 Impact of elevated $\mathrm{CO}_{2}$ on the expression of genes associated with the biosynthesis and catabolism of GABA from glutamate in 'Empire' apple frui under low-temperature/low- $\mathrm{O}_{2}$ storage for up to 16 weeks. Panels a-i represent time-course profiles for GAD1, GAD2, GAD3, GABA-T1,2, GLYR1, GLYR2, SSADH1, SSADH2 and ALA-T, respectively. Storage conditions: $0^{\circ} \mathrm{C}, 2.5 \mathrm{kPa} \mathrm{O}_{2}$ and $5 \mathrm{kPa}(\mathbf{O})$ or $0.03 \mathrm{kPa}(\mathrm{O}) \mathrm{CO}_{2}$. All the data represent the mean of three treatment replicates, each being the average of three subsamples. The error bar above 0 weeks represents the least significant difference at the $P \leq 0.05$ level. Note that the $y$-axis varies among the panels. ALA-T alanine dehydrogenase, GABA-T GABA transaminase, GAD glutamate decarboxylase, GLYR glyoxylate reductase, SSADH succinic semialdehyde dehydrogenase 

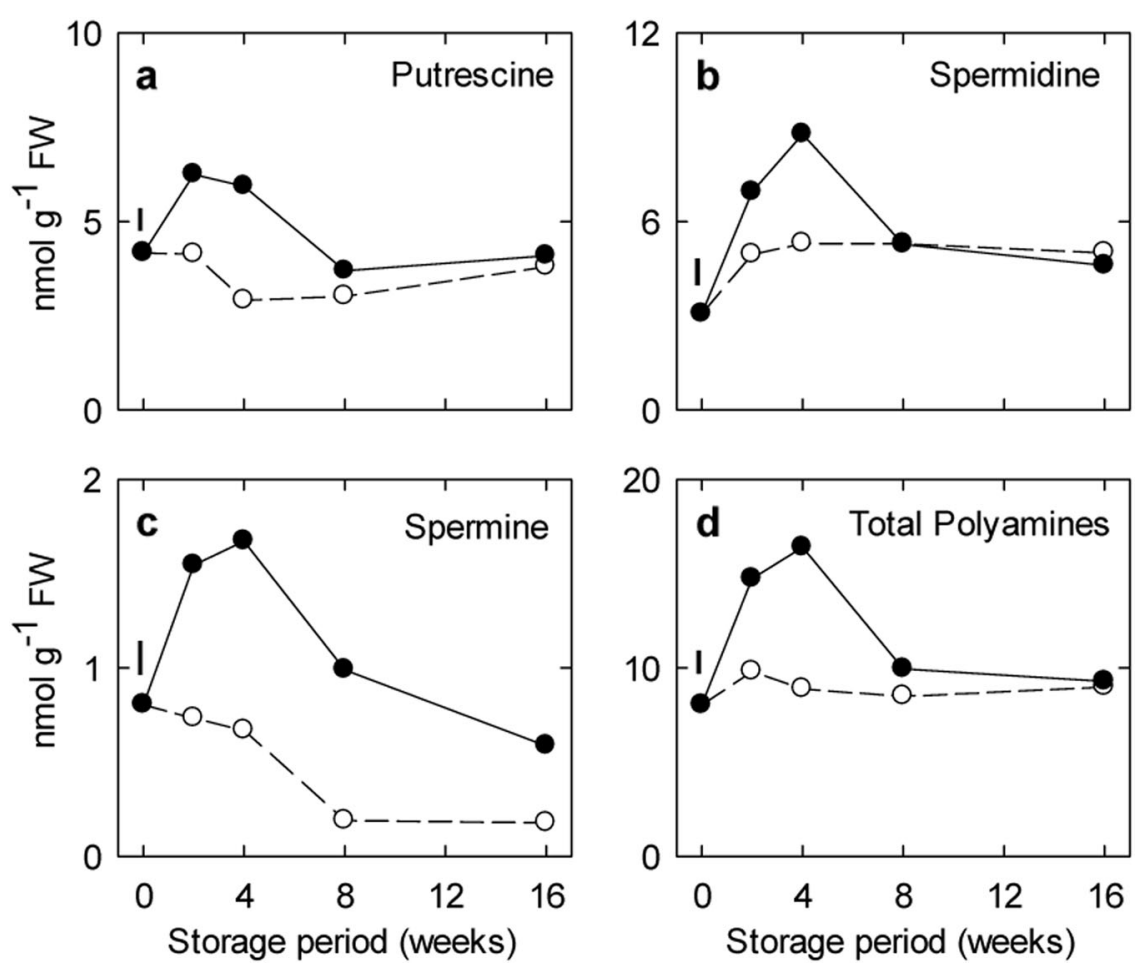

Fig. 4 Impact of elevated $\mathrm{CO}_{2}$ on the polyamine levels in 'Empire' apple fruit under low-temperature/low- $\mathrm{O}_{2}$ storage for up to 16 weeks. Panels a-d represent time-course profiles for putrescine, spermidine, spermine and total polyamines, respectively. Storage conditions: $0{ }^{\circ} \mathrm{C}, 2.5 \mathrm{kPa} \mathrm{O}_{2}$ and $5 \mathrm{kPa}(\mathbf{O})$ or $0.03 \mathrm{kPa}(\mathrm{O}) \mathrm{CO}_{2}$. All the data represent the mean of four treatment replicates, each being the average of three to four subsamples. The error bar above 0 wk represents the least significant difference at the $P \leq 0.05$ level. Note that the $y$-axis varies among the panels

spermine strongly responded to $\mathrm{CO}_{2}$. Many gene transcripts (i.e., GAD2, PAO2, AO4, GLYR2, PAO4, SSADH1, $A L D H 10 A 8, A O 2, G A D 1, G A B A-T$ and $A L D H 10 A 9)$ moderately to strongly responded to storage, and several of these (i.e., GAD2, PAO2, ALDH10A8, AO2) moderately responded to $\mathrm{CO}_{2}$. Other transcripts strongly responded to $\mathrm{CO}_{2}$, but only slightly to storage (i.e., $A L A-T, A O 1$, SSADH2 and GAD3).

\section{Discussion}

\section{Metabolite relationships}

The ratios of reduced to oxidized pyridine dinucleotides in freshly harvested and low-temperature CA-stored 'Empire' apples (Fig. 1) were much higher than in photosynthesizing unstressed Arabidopsis leaves ${ }^{13,33}$, and $A L A-T$ expression was induced and maintained during storage (Fig. 3). Furthermore, the $\mathrm{NADH} / \mathrm{NAD}^{+}$ratio declined over the storage period, and the NADPH/ $\mathrm{NADP}^{+}$ratio increased, particularly during late storage, regardless of the treatment regimen (Fig. 1). These findings are consistent with the idea that intact 'Empire' apples are already in a reduced state and metabolism is $\mathrm{O}_{2}$-limited (i.e., hypoxic) at harvest, and that this becomes increasingly so with storage $\mathrm{e}^{1,16,17,19,20,31}$.
The major amino acids in both freshly harvested and stored fruit were aspartate, asparagine and glutamate (Fig. 2; Supporting Information Table S4), whereas polyamines consisted of similar levels of putrescine and spermidine, together with minor levels of spermine (Fig. 4). TAA and GABA-related amino acids transiently accumulated early in storage, regardless of the $\mathrm{CO}_{2}$ regimen (Fig. 2). This was accompanied by relatively stable levels of polyamines, succinate and GHB with ambient $\mathrm{CO}_{2}$, but transient accumulation of these same metabolites with elevated $\mathrm{CO}_{2}$ (Figs. 2 and 4). Notably, the succinate level further declined thereafter, whereas GABA and GHB increased over the longer term. These findings are in general agreement with previous reports of dynamic changes in proteins, proteolytic activity, amino acids and polyamines in apple fruit stored under low-temperature conditions, in the absence or presence of low $\mathrm{O}_{2}$ and elevated $\mathrm{CO}_{2}{ }^{34-37}$. Thus, it can be suggested that the low temperature stimulated protein hydrolysis during early storage, thereby temporarily increasing the pools of amino acids available for various metabolic processes. The elevated glutamate level in particular seemed to influence the relative level of GABA much more than polyamines, despite lower concentrations of the polyamines. Further 

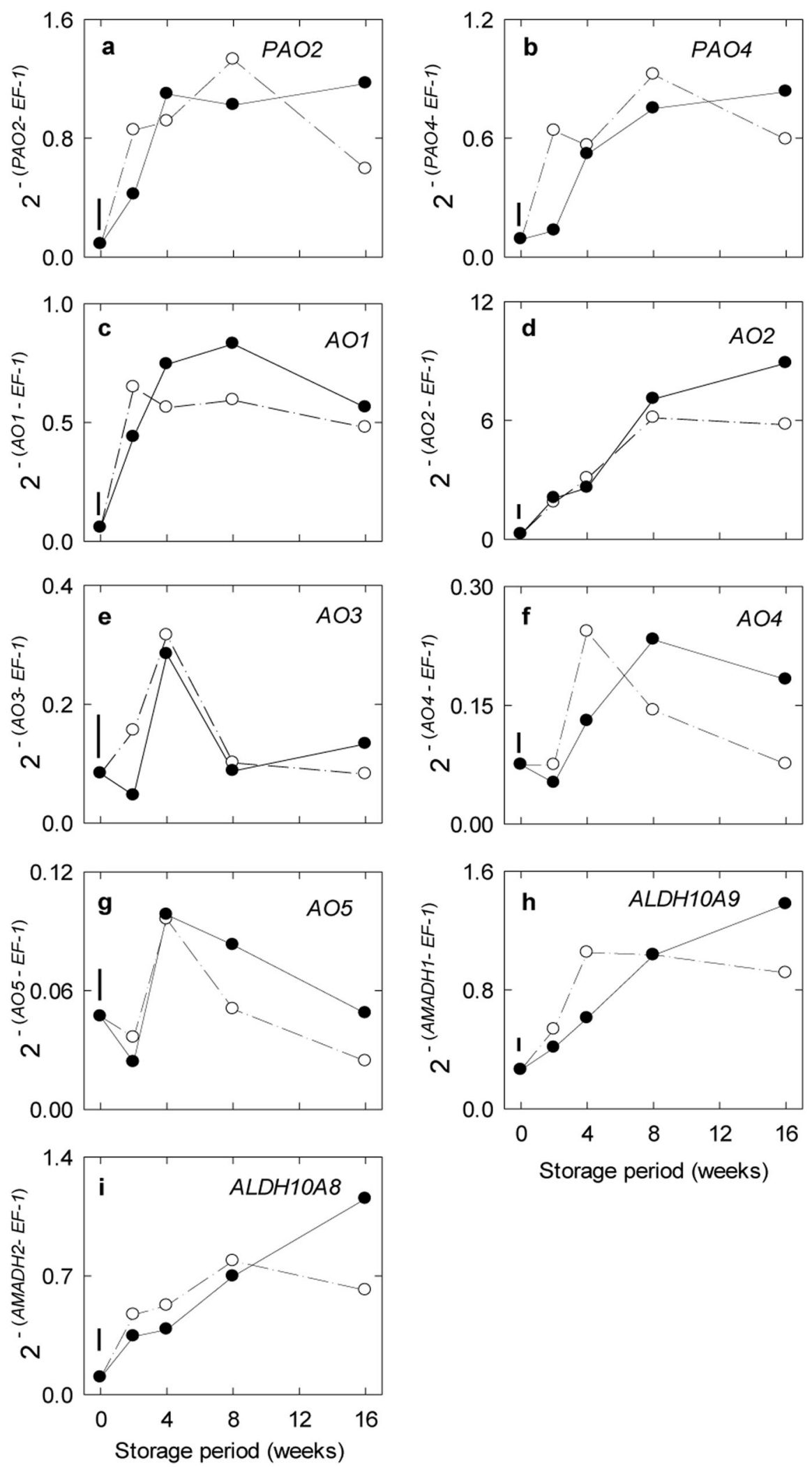

Fig. 5 Impact of elevated $\mathrm{CO}_{2}$ on the expression of genes associated with the catabolism of polyamines to GABA in 'Empire' apple fruit under low-temperature/low- $\mathbf{O}_{\mathbf{2}}$ storage for up to $\mathbf{1 6} \mathbf{w k}$. Panels a-i represent time-course profiles for PAO2, PAO4, AO1, AO2, AO3, AO4, AO5, ALDH10A9 and ALDH10A8, respectively. Storage conditions: $0^{\circ} \mathrm{C}, 2.5 \mathrm{kPa} \mathrm{O}$ and $5 \mathrm{kPa}(\mathbf{O})$ or $0.03 \mathrm{kPa}(\mathrm{O}) \mathrm{CO}_{2}$. All the data represent the mean of three treatment replicates, each being the average of three subsamples. The error bar above 0 wk represents the least significant difference at the $P \leq 0.05$ level. Note that the $y$-axis varies among the panels. AO Amine Oxidase, ALDH aldehyde dehydrogenase, PAO polyamine oxidase 


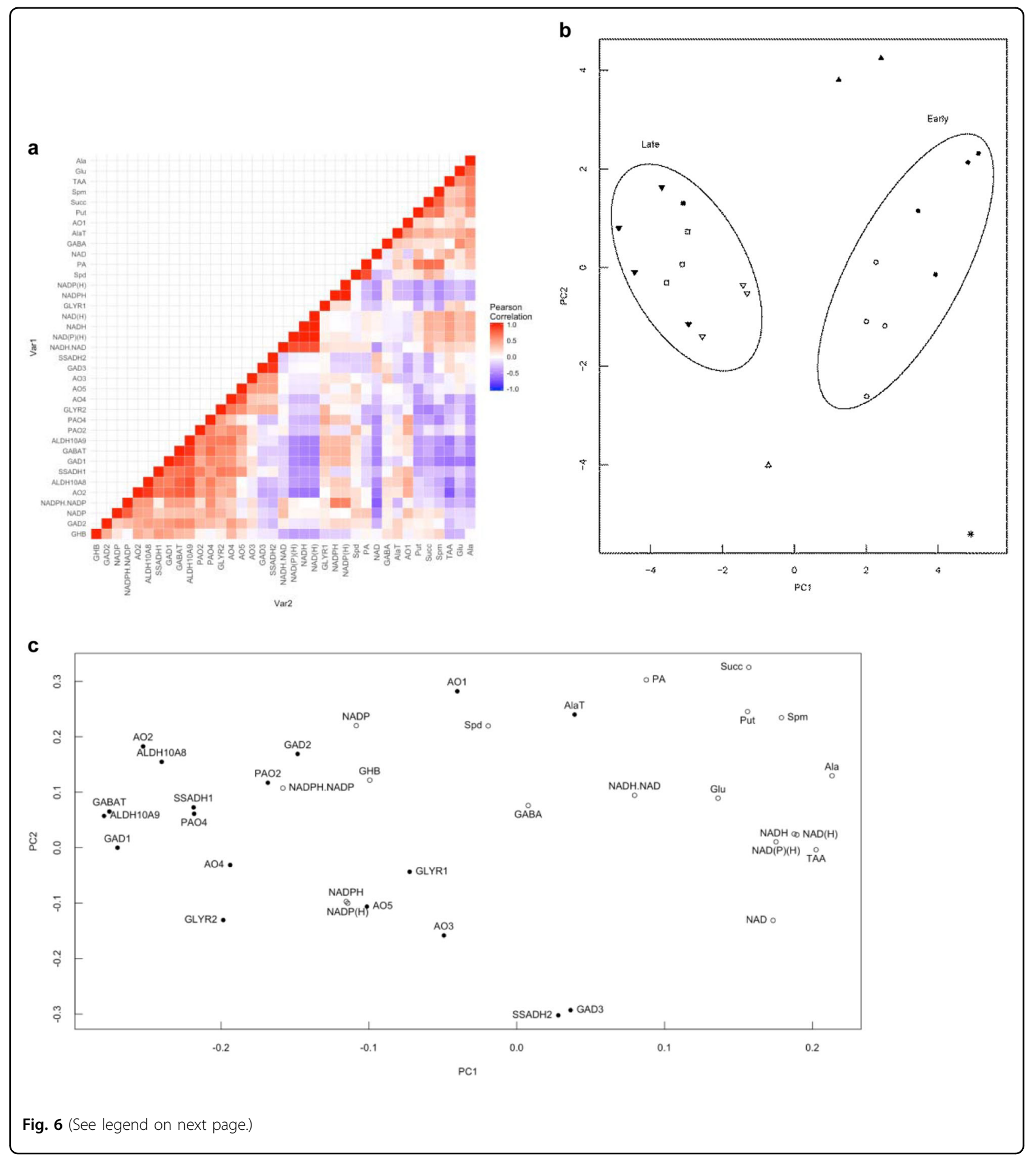

research is required to establish whether this result can be explained by differences in the utilization (e.g., substrate affinity and/or localization) of glutamate by GAD or biosynthetic enzymes for arginine, the primary precursor for polyamines ${ }^{38,39}$. Also, it can be suggested that elevated $\mathrm{CO}_{2}$ had distinct effects on the production of polyamines, as well as succinate and GHB, during early storage, and on GABA and GHB production over the longer term (see "Metabolite-transcript relationships"). Overall, a complex pattern of GABA-related metabolites could be recognized in 'Empire' apple exposed to a combination of low temperature/low $\mathrm{O}_{2}$ and elevated $\mathrm{CO}_{2}$. 
(see figure on previous page)

Fig. 6 Relationships among GABA pathway metabolites and transcripts in 'Empire' apple fruit under low-temperature/low- $\mathrm{O}_{2}$ storage at two $\mathrm{CO}_{2}$ levels for up to 16 wk. a Pearson's correlation analysis. A total of 666 pairs were analysed, from which 68 resulted in significant correlations $(P \leq 0.05)$. Of these, 58 were positive and 10 negative. Each square represents the correlation between each metabolite or transcript in the column and the metabolite or transcript in the corresponding row with a color scale (color scale key at the side of the figure). b Principal component analysis. Score plot: fresh harvest control (*) and all variables at 2 (circles), 4 (triangles), 8 (squares) and 16 (inverted triangles) weeks of storage; $0.03 \mathrm{kPa} \mathrm{CO}_{2}$ (open symbols) and $5 \mathrm{kPa}$ (filled symbols) $\mathrm{CO}_{2}$. The 2-week (early) and 8/16-week (late) harvests are enclosed separately by solid lines. c Principal component analysis. Loading plot of all variables: metabolites (open circles); transcripts (closed circles). The two principal components (PCs) explained 43.4\% of the overall variance (30.2 and 13.2\% for PC1 and PC2, respectively). The further from the origin, the more variables would be influenced by low temperature/low $\mathrm{O}_{2}(\mathrm{PC} 1)$ or elevated $\mathrm{CO}_{2}(\mathrm{PC2})$; variables with a higher loading value for $\mathrm{PC1}$, but lower for $\mathrm{PC} 2$ would be more influenced by low temperature/low $\mathrm{O}_{2}$, whereas variables with a higher loading value for PC2 but a lower loading value for PC1 would be more influenced by elevated $\mathrm{CO}_{2}$. Ala alanine, ALA-T alanine transaminase, ALDH aldehyde dehydrogenase, AO, amine oxidase, GABA 4-aminobutyrate, GABA-T GABA transaminase, GAD glutamate decarboxylase, GHB 4-hydroxybutyrate, Glu glutamate, GLYR glyoxylate reductase, PAO polyamine oxidase, NAD ${ }^{+}$/ NADH oxidized/reduced nicotinamide dinucleotide, NADP ${ }^{+} / \mathrm{NADPH}$ oxidized/reduced nicotinamide dinucleotide phosphate, NAD(H) total oxidized/ reduced nicotinamide dinucleotide, $\operatorname{NADP}(\mathrm{H})$ total oxidized/reduced nicotinamide dinucleotide phosphate, $\operatorname{NAD}(\mathrm{P})(\mathrm{H})$ total oxidized/reduced nicotinamide dinucleotide (phosphate), PA total polyamines, Put putrescine, Spd spermidine, Spm spermine, SSADH succinic semialdehyde dehydrogense, Succ succinate; TAA total amino acids

\section{Transcript relationships}

Figure 7 contextualizes our current understanding of stress-induced GABA production in apple fruit from the decarboxylation of glutamate and the catabolism of polyamines. The route from glutamate to GABA is probably catalyzed by two of the three cytosolic MdGADs (MdGAD1 and MdGAD2), which are abundant and interact with $\mathrm{Ca}^{2+}$-calmodulin ${ }^{24}$. Putrescine and spermidine also represent potential sources of GABA via the metabolite 4-aminobutanal. Spermidine and spermine, respectively, are known to be back-converted to putrescine and/or spermidine in dicotyledonous plants ${ }^{1,4}$, and preliminary assessment here, based on in silico analysis, suggests that specific apple FAD-polyamine oxidases $(\mathrm{PAO} 2,4)$ are peroxisomal (Supplementary Information Figure S1). Five copper AOs are present in 'Empire' apple fruit, but only one of the two most abundant forms (i.e., AO1) is peroxisomal and prefers diamines as

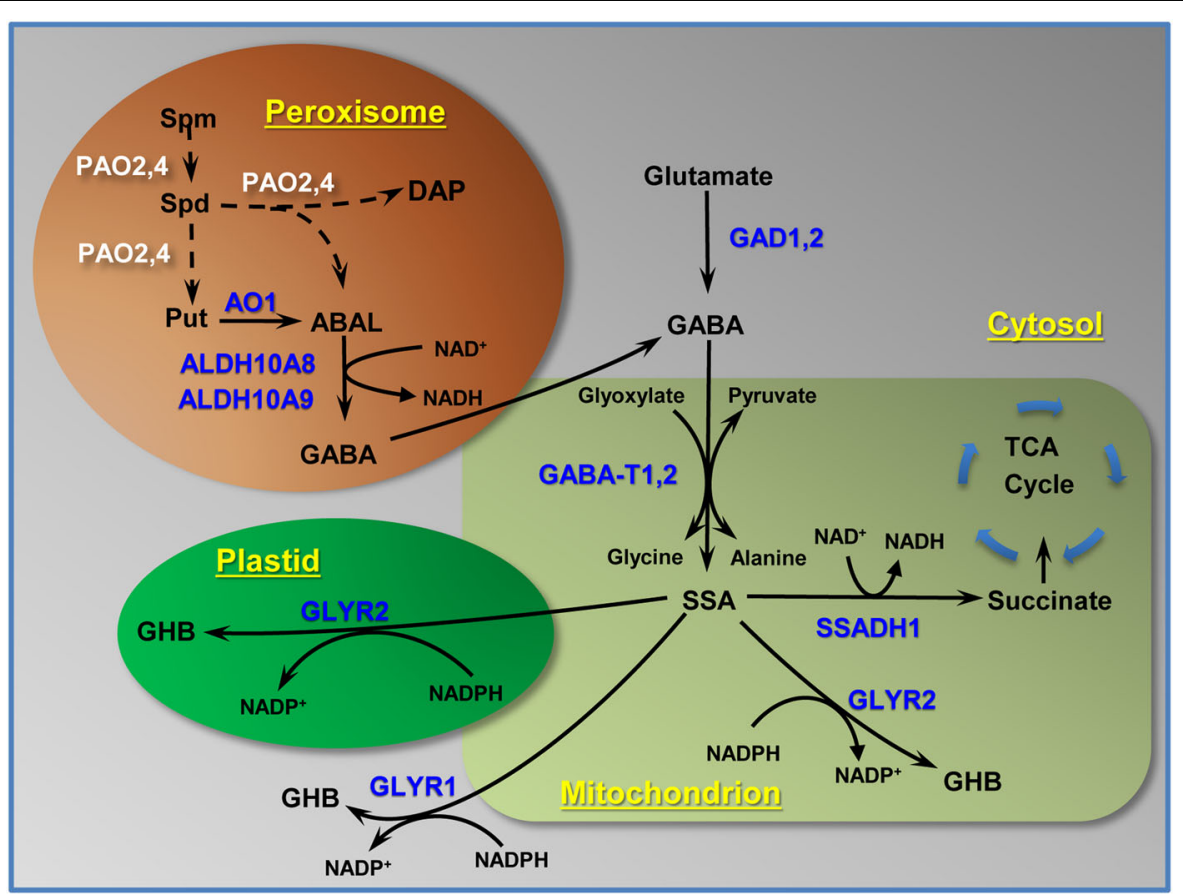

Fig. 7 Model for the induction and subcellular localization of enzymes associated with GABA and GHB metabolism in 'Empire' apple fruit stored under low temperature, low $\mathrm{O}_{2}$ and elevated $\mathrm{CO}_{2}$ conditions. Bold blue lettering represents known biochemically characterized enzymes, whereas bold white lettering and dashed arrows represent putative polyamine oxidases, which were localized to the peroxisome using in silico comparisons with Arabidopsis orthologs (see Supplementary Information Fig. S1). 4-ABAL 4-aminobutanal, DAP 1,3-diaminopropane, SSA succinic semialdehyde, TCA tricarboxylic acid. For other abbreviations, see Fig. 6 
substrates ${ }^{5}$. Two putative peroxisomally-located, $\mathrm{NAD}^{+}$dependent $M d A L D H 10 A s$ can convert 4-aminobutanal to GABA $^{7}$. Therefore, AO1 and the ALDH10As represent a likely path for putrescine oxidation to GABA in apple fruit.

In the present study, the apple fruit genes associated with GABA anabolism from both glutamate and polyamines, and with GABA catabolism to succinate were all co-ordinately upregulated by low temperature/low $\mathrm{O}_{2}$ with ambient $\mathrm{CO}_{2}$ (Figs 3, 5, 6, 7). Furthermore, there was evidence for $\mathrm{CO}_{2}$-upregulated expression of $G A D 2$, AO1, ALDH1OA8 and PAO2 with mid- to long-term storage (Fig. 6). Previous studies have attempted to directly link transcriptome changes to stress-induced increases in GABA levels in plants ${ }^{1,4,40,41}$, For example, a limited number of key GABA pathway genes in Arabidopsis (i.e., GAD4, SSADH and GABP) and tomato fruit (i.e., GAD2,3, but not GAD1, GABA-T, SSADH or GLYR1,2) appear to be upregulated in a co-ordinated manner by cold and elevated $\mathrm{CO}_{2}$, respectively ${ }^{11,42}$. Thus, expression of genes linked to stress-induced GABA metabolism in apple fruit displays some unique regulatory properties and close examination of the corresponding promoter regions could reveal common motifs and elements associated with low temperature, low $\mathrm{O}_{2}$ or elevated $\mathrm{CO}_{2}$.

\section{Metabolite-transcript relationships}

Although transcriptional mechanisms are essential for GABA metabolism to proceed in apple fruit during storage, the increasing abundance of key gene transcripts is probably not the entire explanation for the $\mathrm{CO}_{2}$-stimulated GABA accumulation during late storage (Figs. 2, 3, $4,5,6)$. The accumulation of GABA could also involve cytosolic acidification-mediated or $\mathrm{Ca}^{2+} /$ calmodulinactivated increases in the activities of GAD1 and/or GAD2 ${ }^{1,24,43,44}$. The dramatic loss in polyamine levels over the same period might be linked with the induction of $A O 1$, but given that the activity of the corresponding enzyme relies on molecular $\mathrm{O}_{2}$ for catalysis ${ }^{5,45,46}$, ALDH10As are $\mathrm{NAD}^{+}$-dependent ${ }^{7}$, and CA-stored apple fruit are probably $\mathrm{O}_{2}$ limited $^{16,17}$ with an elevated NAD(P)H/ $\mathrm{NAD}(\mathrm{P})^{+}$ratio (see "Metabolite relationships"), it seems more likely that AO1, PAO2, and ALDH10A8 activities would be restricted in apple fruit and cause the accumulation of the polyamines ${ }^{1}$. Interestingly, both glutamate and alanine pools declined during this period, but they were not markedly affected by the $\mathrm{CO}_{2}$ regimen, providing support for the maintenance in plants of glutamate within narrow concentration limits ${ }^{47}$. Previous research has shown that two GABA peaks are found in rice being germinated under anoxia and the first peak is associated with slight upregulation of at least one of five
GADs and downregulation of both GABA-T and SSADH, whereas a single transient GABA peak is found in chilled Arabidopsis shoots and it is associated with upregulation of both GAD4 and SSADH ${ }^{11}$.

The initial $\mathrm{CO}_{2}$-regulated accumulation of succinate and GHB in apple fruit could not be attributed to elevated expression of GAD1, GAD2, SSADH and GLYR. Notably, the initial accumulation of GHB preceded that of GABA, and the second $\mathrm{CO}_{2}$-regulated accumulation of $\mathrm{GHB}$ was inversely related to succinate accumulation (Figs. 2, 3 and 6). The internal elevated $\mathrm{CO}_{2} / \mathrm{O}_{2}$ environment, rather than $\mathrm{O}_{2}$ alone, probably accounts for the changing redox balance evident in the low-temperature, CA-stored apple fruit (Fig. 1) ${ }^{48,49}$. These reducing conditions could differentially restrict the activities of TCA cycle enzymes, as well as SSADH, and enhance the activities of GLYR over the storage period, thereby modifying the accumulation of succinate and GHB (Figs. 1 and 6) ${ }^{1}$. Unfortunately, metabolite pool sizes are not by themselves very informative in addressing mechanisms ${ }^{44}$. For example, the first peak of GHB is difficult to reconcile on the basis of redox balance alone. Previous studies have reported that succinate accumulates continuously for up to $50 \mathrm{~h}$ in rice germinating under anoxia, with GHB accumulating prior to $\mathrm{GABA}^{11}$, and a lack of correlation between GLYR expression and GHB accumulation in submerged Arabidiopsis $^{18,19}$. Another study has demonstrated that a transient increase in GHB level in shoots of chilled Arabidopsis plants follows a transient increase in GABA and it is independent of GLYR expression ${ }^{11}$. However, there is a concomitant and sustained accumulation of succinate, which can be interpreted as support for the operation of a non-conventional TCA cycle ${ }^{1}$. Additional research is required to determine if stress-induced peroxidation of phospholipids containing 4-hydroxybutyryl chains generates GHB in apple fruit, as it is does in mammals ${ }^{49-53}$, or if the prolonged storage period alters the carbon/ nitrogen balance, resulting in carbon limitation of the TCA cycle and diversion of GABA carbon from succinate to $\mathrm{GHB}^{1,20,54}$.

Together, these findings suggest that both transcriptional and biochemical mechanisms are associated with GABA and GHB metabolism in apple fruit stored under multiple abiotic stress conditions. Exploration of the function of GHB in model plants such as Arabidopsis during exposure to elevated $\mathrm{CO}_{2}$, low $\mathrm{O}_{2}$ and/or low temperature, using single and double overexpression or knockout mutants of GABA-T and GLYR, is warranted.

\section{Disclaimer}

AgroFresh Inc. and the Ontario Apple Growers had no involvement in collection of the data or the decision to publish. 


\section{Acknowledgements}

We apologize to researchers whose original work was not be cited due to space limitations. C.J.B., G.Z.C., J.L. and C.P.T. acknowledge receipt of one or more of the following government and university awards: MITACS Inc.; Ontario Graduate Scholarship; and, the Walter \& Laura Scott Fellowship. We also thank Dr. Katerina Jordan for use of RT-PCR equipment in her laboratory, and three anonymous reviewers for providing valuable suggestions for improvement of the manuscript. The research was supported by funding from the Natural Sciences and Engineering Research Council (NSERC) of Canada as Strategic Project (B.J.S. and G.G.B.), Collaborative Research and Development (G.G.B., B.J.S. and J.R.D.) and Individual Discovery (B.J.S.) Grants, and from the Ontario Ministry of Agriculture, Food \& Rural Affairs, Rohm \& Haas Canada LP (AgroFresh Inc.; B.J.S., G.G.B. and J.R.D.), and the Ontario Apple Growers (B.J.S., G.G.B. and J.R.D.).

\section{Author details}

'Department of Plant Agriculture, University of Guelph, Guelph, Ontario N1G 2W1, Canada. ${ }^{2}$ Department of Mathematical Sciences, Binghamton University, Binghamton, NY 13902, USA. ${ }^{3}$ Ontario Ministry of Agriculture, Food and Rural Affairs, Box 587, 1283 Blueline Rd. at Highway 3, Simcoe, Ontario N3Y 4N5, Canada

\section{Author contributions}

B.J.S. conceived the idea, and B.J.S. and G.G.B. supervised the work. J.R.D. supplied the apples, and J.L., G.R.B. and B.J.S. conducted the experiment; C.J.B. A.Z., G.Z,C., K.L.D. and G.J.H. conducted the metabolite and transcript analyses and related ANOVAs; AZ and C.P.T. identified the novel apple genes; and S.S. conducted the correlation analyses. J.R.D. discussed the project. B.J.S., C.J.B., A.Z., G.Z.C., K.L.D., G.G.B. and S.S. wrote and/or edited the manscript. All authors read and approved the final manuscript.

\section{Conflict of interest}

The authors declare that they have no conflict of interest.

\section{Publisher's note}

Springer Nature remains neutral with regard to jurisdictional claims in published maps and institutional affiliations.

Supplementary Information accompanies this paper at (https://doi.org/ 10.1038/s41438-018-0069-3).

Received: 22 February 2018 Revised: 14 June 2018 Accepted: 15 June 2018 Published online: 01 December 2018

\section{References}

1. Shelp, B. J., Bown, A. W. \& Zarei, A. 4-Aminobutyrate (GABA): metabolite and signal with practical significance. Botany 95, 1015-1032 (2017).

2. Brikis, C. J. et al. Ancient plant glyoxylate/succinic semialdehyde reductases: GLYR1s are cytosolic, whereas GLYR2s are localized to both mitochondria and plastids. Front. Plant Sci. 8, 601 (2017).

3. Zarei, A. et al. Plant glyoxylate/succinic semialdehyde reductases: comparative biochemical properties, function during chilling stress, and subcellular localization. Front. Plant Sci. 8, 1399 (2017).

4. Tiburcio, A. F., Altabella, T., Bitrián, M. \& Alcázar, R. The roles of polyamines during the lifespan of plants: from development to stress. Planta 240, 1-18 (2014).

5. Zarei, A. et al. Apple fruit copper amine oxidase isoforms: peroxisomal MdAO1 prefers diamines as substrates, whereas extracellular MdAO2 exclusively utilizes monoamines. Plant Cell Physiol. 56, 137-147 (2015).

6. Signorelli, S., Dans, P. D., Coitiño, E. L., Borsani, O. \& Monza, J. Connecting proline and $\gamma$-aminobutyric acid in stressed plants through non-enzymatic reactions. PLOS ONE 10, 1-14 (2015).

7. Zarei, A., Trobacher, C. P. \& Shelp, B. J. NAD ${ }^{+}$-aminoaldehyde dehydrogenase candidates for 4-aminobutyrate (GABA) and $\beta$-alanine production during terminal oxidation of polyamines in apple fruit. FEBS Lett. 589, 2695-2700 (2015).
8. Zarei, A., Trobacher, C. P. \& Shelp, B. J. Arabidopsis aldehyde dehydrogenase 10 family members confer salt tolerance through putrescine-derived 4-aminobutyrate (GABA). Sci. Rep. 6, 35115 (2016).

9. Deyman, K. L. et al. Effects of elevated $\mathrm{CO}_{2}$ and 1-methylcyclopropene on storage-related disorders of Ontario-grown 'Empire' apples. Can. J. Plant Sci. 94, 857-865 (2014)

10. Johnson, F. T. \& Zhu, Y. Transcriptome changes in apple peel tissues during $\mathrm{CO}_{2}$ injury symptom development under controlled atmosphere regimens. Hortic. Res. 2, 15061 (2015)

11. Shelp, B. J. et al. Strategies and tools for studying the metabolism and function of $\gamma$-aminobutyrate in plants. II. Integrated analysis. Botany 90, 781-793 (2012).

12. Chiu, G. Z., Shelp, B. J., Bowley, S. R., DeEll, J. R. \& Bozzo, G. G. Controlled atmosphere related injury in 'Honeycrisp' apples is associated with $Y$ aminobutyrate accumulation. Can. J. Plant Sci. 95, 879-886 (2015).

13. Lum, G. B. et al. Pre-storage conditioning ameliorates the negative impact of 1-methylcyclopropene on physiological injury and modifies the response of antioxidants and $y$-aminobutyrate in 'Honeycrisp' apples exposed to controlled-atmosphere conditions. Postharvest Biol. Technol. 116, 115-128 (2016).

14. Deyman, K. L., Brikis, C. J., Bozzo, G. G. \& Shelp, B. J. Impact of 1methylcyclopropene and controlled atmosphere storage on polyamine and $\gamma$ aminobutyrate levels in 'Empire' apple fruit. Front. Plant Sci. 5, 144 (2014).

15. Trobacher, C. P. et al. Catabolism of GABA in apple fruit: Subcellular localization and biochemical characterization of two $\gamma$-aminobutyrate transaminases. Postharvest Biol. Technol. 75, 106-113 (2013).

16. Ho, Q. T. et al. A three-dimensional multiscale model for gas exchange in fruit. Plant Physiol. 155, 1158-1168 (2011).

17. Ho, Q. T., Verboven, P., Verlinden, B. E., Schenk, A. \& Nicolaï, B. M. Controlled atmosphere storage may lead to local ATP deficiency in apple. Postharvest Biol. Technol. 78, 103-112 (2013).

18. Allan, W. L., Simpson, J. P., Clark, S. M. \& Shelp, B. J. Y-Hydroxybutyrate accumulation in Arabidopsis and tobacco plants is a general response to abiotic stress: putative regulation by redox balance and glyoxylate reductase isoforms. J. Exp. Bot. 59, 2555-2564 (2008).

19. Allan, W. L. et al. Glyoxylate reductase and NAD kinase mutants subjected to submergence stress. Botany 90, 51-61 (2012).

20. Lum, G. B., Shelp, B. J., DeEll, J. R. \& Bozzo, G. G. Oxidative metabolism is associated with physiological disorders in fruits stored under multiple environmental stresses. Plant Sci. 245, 143-152 (2016).

21. Chehab, E. W., Eich, E. \& Braam, J. Thigmomorphogenesis: a complex plant response to mechano-stimulation. J. Exp. Bot. 60, 43-56 (2009).

22. Benikhlef, L. et al. Perception of soft mechanical stress in Arabidopsis leaves activates disease resistance. BMC Plant Biol. 13, 133-145 (2013).

23. Allan, W. L. \& Shelp, B. J. Fluctuations of $y$-aminobutyrate, $y$-hydroxybutyrate, and related amino acids in Arabidopsis leaves as a function of the light, dark cycle, leaf age, and N stress. Can. J. Bot. 84, 1339-1346 (2006).

24. Trobacher, C. P. et al. Calmodulin-dependent and calmodulin-independent glutamate decarboxylases in apple fruit. BMC Plant Biol. 13, 144 (2013).

25. Livak, K. J. \& Schmittgen, T. D. Analysis of relative gene expression data using real-time quantitative PCR and the 2(-Delta Delta $C(T))$ method. Methods $\mathbf{2 5}$ 402-408 (2001)

26. Poupard, P., Parisi, L., Campion, C., Ziadi, S. \& Simoneau, P. A wound- and ethephon-inducible PR-10 gene subclass from apple is differentially expressed during infection with a compatible and an incompatible race of Venturia inaequalis. Physiol. Mol. Plant Pathol. 62, 3-12 (2003).

27. Czechowski, T., Stitt, M., Altmann, T. \& Udvardi, M. K. Genome-wide identification and testing of superior reference genes for transcript normalization. Plant Physiol. 139, 5-17 (2005).

28. SAS Institute Inc. Base SAS ${ }^{\circledR} 9.3$ Procedures Guide. (SAS Institute Inc., Cary, NC, 2011).

29. $\mathrm{R}$ Core Team. R: a language and environment for statistical computing ( $R$ Foundation for Statistical Computing, Vienna, Austria. 2016) http://www. Rproject.org/.

30. Benjamini, Y. \& Hochberg, Y. Controlling the false discovery rate: a practical and powerful approach to multiple testing. J. Roy. Stat. Soc. Ser. B 57, 289-300 (1995).

31. Good, A. G. \& Crosby, W. L. Anaerobic induction of alanine aminotransferase in barley root tissue. Plant Physiol. 90, 1305-1309 (1989).

32. Moschou, P. N. et al. Bridging the gap between plant and mammalian polyamine catabolism: a novel peroxisomal polyamine oxidase responsible for 
a full back-conversion pathway in Arabidopsis. Plant Physiol. 147, 1845-1857 (2008).

33. Queval, G. \& Noctor, G. A plate reader method for the measurement of NAD, NADP, glutathione, and ascorbate in tissue extracts: application to redox profiling during Arabidopsis rosette development. Anal. Biochem. 363, 58-69 (2007).

34. Adyanthaya, I., Kwon, Y., Apostolidis, E. \& Shetty, K. Apple postharvest preservation is linked to phenolic content and superoxide dismutase activity. J. Food Biochem. 33, 535-556 (2009).

35. Magné, C., Bonenfant-Magné, M. \& Audran, J. Nitrogenous indicators of postharvest ripening and senescence in apple fruit (Malus domestica Borkh. Cv. Granny Smith). Intern. J. Plant Sci. 158, 811-817 (1997).

36. Feng, F. Li, M., Ma, F. \& Cheng, L. Effects of location within the tree canopy on carbohydrates, organic acids, amino acids and phenolic compounds in the fruit peel and flesh from three apple (Malus $x$ domestica) cultivars. Hortic. Res. 1 14019 (2014).

37. Shi, Y., Jiang, L., Zhang, L., Kang, R. \& Yu, Z. Dynamic changes in proteins during apple (Malus x domestica) fruit ripening and storage. Hortic. Res. 1, 6 (2014).

38. Scott-Taggart, C. P., Van Cauwenberghe, O. R., McLean, M. D. \& Shelp, B. J. Regulation of $\gamma$-aminobutyric acid synthesis in situ by glutamate availability. Physiol. Plant. 106, 363-369 (1999).

39. Winter, G., Todd, C. D., Trovato, M., Forlani, G. \& Funck, D. Physiological implications of arginine metabolism in plants. Front. Plant Sci. 6, 534 (2015).

40. Fait, A., Fromm, H., Walter, D., Galili, G. \& Fernie, A. R. Highway or byway: the metabolic role of the GABA shunt in plants. Trends Plant. Sci. 13, 14-19 (2008).

41. Zarei, A., Chiu, G. Z., Yu, G., Trobacher, C. P. \& Shelp, B. J. Salinity-regulated expression of genes involved in GABA metabolism and signaling. Botany $\mathbf{9 5}$, 621-627 (2017)

42. Deewatthanawong, R., Rowell, P. \& Watkins, C. B. Y-Aminobutyric acid (GABA) metabolism in $\mathrm{CO}_{2}$ treated tomatoes. Postharvest Biol. Technol. 57, 97-105 (2010).
43. Kinnersley, A. M. \& Turano, F. J. Y-Aminobutyric acid (GABA) and plant responses to stress. Crc. Crit. Rev. Plant. Sci. 19, 479-509 (2000).

44. Shelp, B. J., Bozzo, G. G., Trobacher, C. P., Chiu, G. \& Bajwa, V. S. Strategies and tools for studying the metabolism and function of $y$-aminobutyrate in plants. I. Pathway structure. Botany 90, 651-668 (2012).

45. Juda, G. A., Shepard, E. M., Elmore, B. O. \& Dooley, D. M. A comparative study of the binding and inhibition of four copper-containing amine oxidases by azide: Implications for the role of copper during the oxidative half-reaction. Biochemistry 45, 8788-8800 (2006).

46. Mukherjee, A. et al. An inner-sphere mechanism for molecular oxygen reduction catalyzed by copper amine oxidases. J. Am. Chem. Soc. 23, 9459-9473 (2008).

47. Forde, B. G. \& Lea, P. J. Glutamate in plants: metabolism, regulation and signalling. J. Exp. Bot. 58, 2339-2358 (2007).

48. Mathooko, F. M. Regulation of respiratory metabolism in fruits and vegetables by carbon dioxide. Postharvest Biol. Technol. 9, 247-264 (1996).

49. Tcherkez, $\mathrm{G}$. et al. Respiratory metabolism of illuminated leaves depends on $\mathrm{CO}_{2}$ and $\mathrm{O}_{2}$ conditions. Proc. Natl Acad. Sci. USA 105, 797-802 (2008).

50. Tokumura, A., Tanaka, T., Yotsumoto, T. \& Tsukatani, H. Identification of sn-2-whydroxycarboxylate-containing phospholipids in a lipid extract from bovine brain. Biochem. Biophys. Res. Commun. 177, 466-473 (1991).

51. Tanaka, T., Minamino, H., Unezaki, S., Tsukatani, H. \& Tokumura, A. Formation of platelet-activating factor-like phospholipids by $\mathrm{Fe}^{2+} /$ ascorbate/EDTA-induced lipid peroxidation. Biochim. Biophys. Acta 1166, 264-274 (1993).

52. Mamelak, M. \& Kuksis, A. Gammahydroxybutyrate and lipid peroxidation. Int News Fat, Oils, Relat. Mater. 17, 607-610 (2006).

53. Mamelak, M. Alzheimer's disease, oxidative stress and gammahydroxybutyrate. Neurobiol. Aging 28, 1340-1360 (2007).

54. Renault, $\mathrm{H}$. et al. $\gamma$-Aminobutyric acid transaminase deficiency impairs central carbon metabolism and leads to cell wall defects during salt stress in Arabidopsis roots. Plant Cell Environ. 36, 1009-1018 (2013). 